\title{
No association between losartan use and acute pancreatitis in hypertensive patients
}

\author{
Shih-Wei Lai, ${ }^{1,2}$ Hsien-Feng Lin, ${ }^{2,3}$ Cheng-Li Lin, ${ }^{1,4}$ Kuan-Fu Liao ${ }^{5,6,7}$
}

${ }^{1}$ College of Medicine, China Medical University, Taichung, Taiwan

2Department of Family Medicine, China Medical University Hospital, Taichung, Taiwan

${ }^{3}$ School of Chinese Medicine China Medical University,

Taichung, Taiwan

${ }^{4}$ Management Office for Health

Data, China Medical University Hospital, Taichung, Taiwan

${ }^{5}$ College of Medicine, Tzu Chi University, Hualien, Taiwan ${ }^{6}$ Graduate Institute of Integrated Medicine, China Medical University, Taichung,

Taiwan

${ }^{7}$ Department of Internal Medicine, Taichung Tzu Chi General Hospital, Taichung, Taiwan

Correspondence to Dr Kuan-Fu Liao, Department of Internal Medicine, Taichung Tzu Chi General Hospital, No 66, Sec. 1, Fongsing Road, Tanzi District, Taichung City 427, Taiwan;

kuanfuliaog@gmail.com

S-WL and H-FL contributed equally.

Received 6 November 2015 Revised 17 March 2016 Accepted 21 April 2016 Published Online First 5 May 2016

\begin{abstract}
Background and objective Clinical evidence is scarce about the relationship between losartan use and acute pancreatitis. We therefore conducted a populationbased case-control study using the database from the Taiwan National Health Insurance Program to investigate this question.
\end{abstract}

Methods The study consisted of 1449 hypertensive subjects aged 20-84 years with a first episode of acute pancreatitis during the period 2000-2011 as the case group and 2479 hypertensive subjects without acute pancreatitis as the control group. Both the case and control groups were matched for sex, age, comorbidities and index year of acute pancreatitis diagnosis. According to the history of losartan prescription before the date of diagnosis of acute pancreatitis, subjects who had never received a prescription for losartan were defined as 'never use of losartan', those whose last remaining losartan tablet was detected within 7 days before the date of diagnosis of acute pancreatitis were defined as 'current use of losartan' and those whose last remaining tablet of losartan was detected $\geq 8$ days before the date of diagnosis of acute pancreatitis were defined as 'late use of losartan'. ORs and $95 \% \mathrm{Cls}$ were measured to investigate the risk of acute pancreatitis associated with losartan use by the multivariable unconditional logistic regression model.

Results After adjustment for potentially confounding factors, the adjusted OR of acute pancreatitis was 0.96 ( $95 \% \mathrm{Cl} 0.68$ to 1.37 ) for subjects with current use of losartan compared with those with never use of losartan, but the difference was not statistically significant. For subjects with late use of losartan the adjusted OR of acute pancreatitis was $1.05(95 \% \mathrm{Cl}$ 0.80 to 1.37 ), which also was not statistically significant. Conclusions No significant association can be detected between losartan use and acute pancreatitis in hypertensive patients. More research is required to determine the potential role of losartan in the risk of acute pancreatitis.

\section{INTRODUCTION}

Losartan, the first angiotensin II antagonist available in the market, is mainly prescribed for the treatment of hypertension, with good efficacy and tolerability. ${ }^{12}$ Clinically, very few adverse events of losartan use have been reported; those reported include hepatotoxicity, bullous pemphigoid and angioedema. ${ }^{3-5}$ Additionally, three cases of acute pancreatitis have been reported to be potentially related to losartan use. ${ }^{6-8}$ The US Food and Drug Administration has shown that, among 13173 people reporting side effects when taking losartan since 2001-2012, $20(0.15 \%)$ had acute pancreatitis, but the causal effect was not elucidated. ${ }^{9}$
Although numerous factors have been found to be related to acute pancreatitis including alcohol, biliary stones and type 2 diabetes mellitus, ${ }^{10}{ }^{11}$ about $0.1-2 \%$ of acute pancreatitis cases were potentially related to medication use. ${ }^{12}{ }^{13}$ However, clinical evidence on the relationship between losartan use and acute pancreatitis based on systematic population-based research is scarce. If losartan use might be associated with acute pancreatitis, clinicians should take this drug into consideration in search of the aetiologies of acute pancreatitis. We therefore conducted a populationbased case-control study to investigate this question.

\section{METHODS}

\section{Design and study population}

We conducted a population-based case-control study using the database from the Taiwan National Health Insurance Program. This programme launched on 1 March 1995 and covers about 99\% of the 23 million citizens living in Taiwan. ${ }^{14}$ The details of the programme have been well documented in previous papers. ${ }^{15-21}$ This study was approved by the Ethics Review Board of China Medical University and Hospital in Taiwan (CMUH-104-REC2-115).

\section{Cases and controls}

Hypertensive subjects aged 20-84 years with a first episode of acute pancreatitis according to the International Classification of Diseases 9th Revision Clinical Modification (ICD-9 code 577.0) during the period 2000-2011 were selected as the case group. The index date for each case was defined as the date on which acute pancreatitis was diagnosed. Hypertensive subjects without a diagnosis of acute pancreatitis were randomly selected from the same database as the control group. Both case and control groups were matched for sex, age (every 5 years), comorbidities and the index year of diagnosing acute pancreatitis. To decrease biased results, subjects who had chronic pancreatitis (ICD-9 code 577.1) or pancreatic cancer (ICD-9 code 157) before the date acute pancreatitis was diagnosed were excluded from the study. Subjects who had prescriptions for other angiotensin II receptor antagonists available in Taiwan were also excluded from the study.

\section{Comorbidities}

Comorbidities potentially associated with acute pancreatitis before the index date were included as follows: alcohol-related disease (ICD-9 codes 291, 303, 305.00, 305.01, 305.02, 305.03, 790.3 and V11.3), biliary stone (ICD-9 code 574),
To cite: Lai S-W, Lin H-F,
Lin C-L, et al. Eur J Hosp

Pharm 2017;24:120-123. 
cardiovascular disease including coronary artery disease, heart failure, cerebrovascular disease and peripheral atherosclerosis (ICD-9 codes 410-414, 428, 430-438 and 440-448), chronic kidney disease (ICD-9 codes 585-586 and 588.8-588.9), chronic obstructive pulmonary disease (ICD-9 codes 491, 492, 493 and 496), diabetes mellitus (ICD-9 code 250), hepatitis B (ICD-9 codes V02.61, 070.20, 070.22, 070.30 and 070.32), hepatitis C (ICD-9 codes V02.62, 070.41, 070.44, 070.51 and 070.54), hyperparathyroidism (ICD-9 code 252.0) and hypertriglyceridaemia (ICD-9 code 272.1). The ICD-9 code accuracy of these comorbidities has been well reviewed in previous studies. $^{22-32}$ A prescription history of other antihypertensive agents available in Taiwan was also included in the study.

\section{Definition of losartan exposure}

According to the history of losartan prescription before the date of diagnosis of acute pancreatitis, we could estimate the last remaining tablet for losartan. The definition of losartan use was adapted from previous studies. ${ }^{27}$ 33-35 Subjects whose last remaining tablet of losartan was detected within 7 days before the date of diagnosis of acute pancreatitis or who still had losartan tablets at the date on which acute pancreatitis was diagnosed were defined as 'current use of losartan'. Subjects whose last remaining losartan tablet was detected $\geq 8$ days before the date of diagnosis of acute pancreatitis were defined as 'late use of losartan'. Subjects who had never received a prescription for losartan were defined as 'never use of losartan'.

\section{Statistical analysis}

The distributions of sex, age, use of losartan, use of other antihypertensive agents and comorbidities were compared between the case and control groups using the $\chi^{2}$ test and Fisher exact test for categorised variables and the $t$ test for continuous variables. All variables were first included in the univariable unconditional logistic regression model and those found to be significant were further examined in the multivariable unconditional logistic regression model. ORs and 95\% CIs were measured to investigate the risk of acute pancreatitis associated with losartan use. All data processing and statistical analyses were performed with SAS software V.9.2 (SAS Institute, Cary, North Carolina, USA). A two-tailed $\mathrm{p}$ value of $<0.05$ was considered statistically significant.

\section{RESULTS}

\section{Characteristics of the study population}

Table 1 shows the distributions of sex, age, use of losartan, use of other antihypertensive agents and comorbidities between the case and control groups. This study consisted of 1449 cases with acute pancreatitis and 2479 controls without acute pancreatitis, with a similar sex and age distribution. The mean \pm SD ages of the study subjects were $59.4 \pm 14.3$ years for the case group and 59.0 \pm 14.6 years for the control group, without statistical significance ( $t$ test, $p=0.47$ ). There was no significant difference in current use or late use of losartan between the case and control groups $\left(\chi^{2}\right.$ test, $\left.p=0.75\right)$. The case group had higher proportions of ever use of other antihypertensive agents (94.41\% vs $92.05 \%)$, alcohol-related disease $(10.6 \%$ vs $7.70 \%)$, biliary stone $(26.4 \%$ vs $22.7 \%)$, chronic kidney disease $(6.42 \%$ vs $4.03 \%)$, hepatitis B $(4.69 \%$ vs $2.22 \%)$, hepatitis C $(4.00 \%$ vs $1.82 \%)$, hyperparathyroidism $(0.48 \%$ vs $0.04 \%)$ and hypertriglyceridaemia $(2.83 \%$ vs $1.13 \%)$ than the control group, which was statistically significant $\left(\chi^{2}\right.$ test and Fisher exact test, $\mathrm{p}<0.05)$.
Table 1 Characteristics of cases with acute pancreatitis and controls from 2000 to 2011

\begin{tabular}{|c|c|c|c|c|c|}
\hline \multirow[b]{2}{*}{ Variable } & \multicolumn{2}{|c|}{$\begin{array}{l}\text { Cases } \\
(\mathrm{N}=1449)\end{array}$} & \multicolumn{2}{|c|}{$\begin{array}{l}\text { Controls } \\
(\mathrm{N}=2479)\end{array}$} & \multirow[b]{2}{*}{ p Value* } \\
\hline & $\mathrm{n}$ & $(\%)$ & n & $(\%)$ & \\
\hline Sex & & & & & 0.89 \\
\hline Female & 549 & (37.9) & 945 & (38.1) & \\
\hline Male & 900 & $(62.1)$ & 1534 & $(61.9)$ & \\
\hline Age group (years) & & & & & 0.80 \\
\hline 20-39 & 159 & $(11.0)$ & 257 & $(10.4)$ & \\
\hline $40-64$ & 723 & $(49.9)$ & 1234 & $(49.8)$ & \\
\hline $65-84$ & 567 & (39.1) & 988 & (39.9) & \\
\hline Age (years), mean (SD)† & 59.4 & $(14.3)$ & 59.0 & $(14.6)$ & 0.47 \\
\hline Losartan & & & & & 0.75 \\
\hline Never use & 1300 & (89.7) & 2238 & $(90.3)$ & \\
\hline Current use & 52 & (3.6) & 90 & (3.6) & \\
\hline Late use & 97 & (6.7) & 151 & (6.1) & \\
\hline $\begin{array}{l}\text { Other antihypertensive } \\
\text { agents }\end{array}$ & & & & & 0.006 \\
\hline Never use & 81 & (5.59) & 197 & (7.95) & \\
\hline Ever use & 1368 & $(94.41)$ & 2282 & $(92.05)$ & \\
\hline \multicolumn{6}{|l|}{$\begin{array}{l}\text { Comorbidities before index } \\
\text { date }\end{array}$} \\
\hline Alcohol-related disease & 154 & (10.6) & 191 & $(7.70)$ & 0.002 \\
\hline Biliary stone & 383 & $(26.4)$ & 563 & $(22.7)$ & 0.009 \\
\hline Cardiovascular disease & 623 & $(43.0)$ & 1048 & $(42.3)$ & 0.66 \\
\hline Chronic kidney disease & 93 & $(6.42)$ & 100 & $(4.03)$ & $<0.001$ \\
\hline $\begin{array}{l}\text { Chronic obstructive } \\
\text { pulmonary disease }\end{array}$ & 364 & $(25.1)$ & 596 & $(24.0)$ & 0.45 \\
\hline Diabetes mellitus & 367 & $(25.3)$ & 567 & (22.9) & 0.08 \\
\hline Hepatitis B & 68 & $(4.69)$ & 55 & $(2.22)$ & $<0.001$ \\
\hline Hepatitis C & 58 & $(4.00)$ & 45 & $(1.82)$ & $<0.001$ \\
\hline Hyperparathyroidism $\ddagger$ & 7 & $(0.48)$ & 1 & $(0.04)$ & 0.005 \\
\hline Hypertriglyceridaemia & 41 & $(2.83)$ & 28 & (1.13) & $<0.001$ \\
\hline
\end{tabular}

Data are presented as the number of subjects in each group with percentages given in parentheses, or mean with SD given in parentheses.

${ }^{*} \chi^{2}$ test.

tt test comparing subjects with and without acute pancreatitis.

\#Fisher exact test.

\section{Acute pancreatitis associated with losartan use}

After adjusting for other antihypertensive agents, alcohol-related disease, biliary stone, chronic kidney disease, hepatitis B, hepatitis C, hyperparathyroidism and hypertriglyceridaemia, the multivariable unconditional logistic regression model demonstrated that the adjusted OR of acute pancreatitis was $0.96(95 \%$ CI 0.68 to 1.37) for subjects with current use of losartan compared with subjects with never use of losartan, which was not statistically significant. The adjusted OR of acute pancreatitis was 1.05 (95\% CI 0.80 to 1.37) for subjects with late use of losartan, which also was not statistically significant (table 2 ).

\section{DISCUSSION}

Although more than $90 \%$ of patients had used other antihypertensive agents in both groups, to date, three case reports of acute pancreatitis have been found to be potentially related to losartan use. ${ }^{6-8}$ That is why we focus on the relationship between losartan use and acute pancreatitis in hypertensive patients by using population-based claims data. In this wellmatched case-control study we observed no significant association between losartan use and acute pancreatitis, irrespective of whether patients were current users or late users of losartan. 
Table 2 ORs and 95\% Cls for acute pancreatitis associated with losartan use from 2000 to 2011

\begin{tabular}{|c|c|c|c|c|}
\hline \multirow[b]{2}{*}{ Variable } & \multicolumn{2}{|c|}{ Crude } & \multicolumn{2}{|c|}{ Adjusted* } \\
\hline & OR & $(95 \% \mathrm{Cl})$ & OR & $(95 \% \mathrm{Cl})$ \\
\hline \multicolumn{5}{|c|}{ Losartan use (never use as reference) } \\
\hline Current use & 1.00 & (0.70 to 1.41 ) & 0.96 & (0.68 to 1.37 ) \\
\hline Late use & 1.11 & (0.85 to 1.44$)$ & 1.05 & (0.80 to 1.37$)$ \\
\hline
\end{tabular}

Previous studies in Europe have reported the possibility of a protective effect of angiotensin II antagonists in acute pancreatitis, but they did not reach statistical significance. ${ }^{36} 37$ There seems to be a conflicting result between case reports and epidemiological data on the association between losartan use and acute pancreatitis.

We have reviewed and summarised the current knowledge on this question. First, the local renin-angiotensin system in the pancreas plays an important role in regulation of pancreatic acinar cell digestive enzyme secretion and pancreatic ducts. ${ }^{38-40}$ In animal models, losartan may decrease pancreatic parenchymal necrosis and neutrophil infiltration, inhibit acinar digestive enzyme secretion and further ameliorate the pancreatic injury in experimental acute pancreatitis. ${ }^{38} 4142$ These data suggest that losartan may protect against acute pancreatitis, which can partially explain why previous epidemiological studies have shown that losartan use is associated with a non-significantly reduced risk of acute pancreatitis. ${ }^{36}{ }^{37}$ Second, losartan may induce angioedema and rash. ${ }^{3} 43$ We think that losartan may also induce hypersensitivity of the pancreas, which leads to the onset of acute pancreatitis. This can partially explain the mechanism of case reports. Therefore, the literature is somewhat ambivalent about potential mechanisms by which losartan may promote or protect against acute pancreatitis. Further research is needed to elucidate the underlying mechanism.

\section{Limitations and strengths of the study}

This study has some limitations. First, the underlying causes of acute pancreatitis were not recorded in the database, so there is no knowing how many patients of acute pancreatitis were really caused by losartan. Second, we were not sure whether the patients actually took losartan. This is an almost universal limitation of administrative databases. Instead, we used losartan prescriptions for analysis. There could be a small gap between use of medication and prescription of medication. Third, some known risk factors for acute pancreatitis were not recorded in the database such as alcohol, smoking and body mass index. We included alcohol-related disease instead of alcohol and included chronic obstructive pulmonary disease instead of smoking. Alcohol-related disease does not necessarily indicate similar consumption of alcohol (quantity, frequency, pattern (binge vs daily use)) among cases and controls. Thus, it cannot be inferred that both groups had similar exposure to alcohol. Fourth, it is very difficult to include all potentially concurrent medications for analysis. We focus on losartan use only and acute pancreatitis. Fifth, a retrospective case-control study design can only demonstrate a statistical association with no conclusion about causation. Such a design is not sufficiently robust for the inference made.
Some strengths of this study should also be mentioned. Losartan is the first angiotensin II antagonist available in the market. It has more research to be reviewed, which is why we selected losartan for study. This is a potentially important report on a retrospective case-control study examining the association of losartan use with acute pancreatitis after excluding those with use of other angiotensin II receptor antagonists. The methodology, data and interpretation are fairly appropriate. The findings of this study are of interest, given the scarcity of clinical data around this question.

\section{CONCLUSION}

We conclude that no significant association can be detected between losartan use and acute pancreatitis in hypertensive patients. More research is required to illustrate the potential role of losartan in the risk of acute pancreatitis.

\section{Key messages}

What is already known on this subject

- A few cases with acute pancreatitis have been reported to be potentially related to losartan use.

- Clinical evidence based on systematic research is scarce about the relationship between losartan use and acute pancreatitis.

\section{What this study adds}

- This systematic population-based case-control study demonstrates that no significant association can be detected between losartan use and acute pancreatitis in hypertensive patients.

Contributors S-WL planned and conducted the study, substantially contributed to the conception of the article, initiated the draft of the article and critically revised it. $\mathrm{H}-\mathrm{FL}$ and $\mathrm{C}-\mathrm{LL}$ conducted the data analysis and critically revised the article. $\mathrm{K}-\mathrm{FL}$ planned and conducted the study, participated in the data interpretation and critically revised the article.

Funding This study is supported in part by Taiwan Ministry of Health and Welfare Clinical Trial and Research Center of Excellence (MOHW105-TDU-B-212-133019), China Medical University Hospital, Academia Sinica Taiwan Biobank Stroke Biosignature Project (BM 10501010037), National Research Program for Biopharmaceuticals (NRPB) Stroke Clinical Trial Consortium (MOST 104-2325-B-039 -005), Tseng-Lien Lin Foundation, Taichung, Taiwan, Taiwan Brain Disease Foundation, Taipei, Taiwan, and Katsuzo and Kiyo Aoshima Memorial Funds, Japan. These funding agencies did not influence the study design, data collection and analysis, decision to publish or preparation of the manuscript.

\section{Competing interests None declared.}

Ethics approval This study was approved by the Ethics Review Board of China Medical University and Hospital in Taiwan (CMUH-104-REC2-115).

Provenance and peer review Not commissioned; externally peer reviewed.

\section{REFERENCES}

1 Goa KL, Wagstaff AJ. Losartan potassium: a review of its pharmacology, clinical efficacy and tolerability in the management of hypertension. Drugs 1996;51:820-45.

2 Gavras HP, Salerno CM. The angiotensin II type 1 receptor blocker losartan in clinical practice: a review. Clin Ther 1996;18:1058-67.

3 Acker CG, Greenberg A. Angioedema induced by the angiotensin II blocker losartan. N Engl J Med 1995;333:1572.

4 Nygaard B, Strandgaard S. Marked hepatotoxicity associated with losartan treatment. Blood Press 1996;5:190-1.

5 Saraceno R, Citarella L, Spallone G, et al. A biological approach in a patient with psoriasis and bullous pemphigoid associated with losartan therapy. Clin Exp Dermatol 2008;33:154-5. 
6 Bosch X. Losartan-induced acute pancreatitis. Ann Intern Med 1997;127:1043-4.

7 Birck R, Keim V, Fiedler F, et al. Pancreatitis after losartan. Lancet 1998;351:1178.

8 Arellano L, Altaba A, Santamaria C, et al. [Acute pancreatitis in a patient treated with losartan]. Aten Primaria 2014:46:316-17.

9 eHealthMe study from FDA and social media reports. Review: could losartan cause acute pancreatitis? http://www.ehealthme.com/print/ds15736576 (cited 1 March 2016).

10 Lai SW, Muo CH, Liao KF, et al. Risk of acute pancreatitis in type 2 diabetes and risk reduction on anti-diabetic drugs: a population-based cohort study in Taiwan. Am J Gastroenterol 2011;106:1697-704.

11 Cavestro GM, Leandro G, Di Leo $M$, et al. A single-centre prospective, cohort study of the natural history of acute pancreatitis. Dig Liver Dis 2015;47:205-10.

12 Ksiadzyna D. Drug-induced acute pancreatitis related to medications commonly used in gastroenterology. Eur J Intern Med 2011;22:20-5.

13 Hung WY, Abreu Lanfranco 0. Contemporary review of drug-induced pancreatitis: a different perspective. World J Gastrointest Pathophysiol 2014;5:405-15.

14 National Health Insurance Research Database, Taiwan (English version). http://nhird. nhri.org.tw/en/index.html (cited 1 February 2016).

15 Lai SW, Liao KF, Liao CC, et al. Polypharmacy correlates with increased risk for hip fracture in the elderly: a population-based study. Medicine (Baltimore) 2010:89:295-9.

16 Hung SC, Liao KF, Lai SW, et al. Risk factors associated with symptomatic cholelithiasis in Taiwan: a population-based study. BMC Gastroenterol 2011:11:111.

17 Chen HY, Lai SW, Muo CH, et al. Ethambutol-induced optic neuropathy: a nationwide population-based study from Taiwan. $\mathrm{Br} J$ Ophthalmol 2012;96:1368-71.

18 Lai HC, Tsai IJ, Chen PC, et al. Gallstones, a cholecystectomy, chronic pancreatitis, and the risk of subsequent pancreatic cancer in diabetic patients: a population-based cohort study. J Gastroenterol 2013;48:721-7.

19 Lai HC, Chang SN, Lin CC, et al. Does diabetes mellitus with or without gallstones increase the risk of gallbladder cancer? Results from a population-based cohort study. J Gastroenterol 2013;48:856-65.

20 Lai HC, Lin CC, Cheng KS, et al. Increased incidence of gastrointestinal cancers among patients with pyogenic liver abscess: a population-based cohort study. Gastroenterology 2014;146:129-37.e1

21 Yang SP, Muo $\mathrm{CH}$, Wang IK, et al. Risk of type 2 diabetes mellitus in female breast cancer patients treated with morphine: a retrospective population-based time-dependent cohort study. Diabetes Res Clin Pract 2015;110:285-90.

22 Lai SW, Lin CL, Liao KF. Rosuvastatin and risk of acute pancreatitis in a population-based case-control study. Int J Cardiol 2015;187:417-20.

23 Lai SW, Lai HC, Lin CL, et al. Zopiclone use associated with increased risk of acute pancreatitis: a case-control study in Taiwan. Int J Clin Pract 2015;69:1275-80.

24 Hung SC, Hung SR, Lin CL, et al. Use of celecoxib correlates with increased relative risk of acute pancreatitis: a case-control study in Taiwan. Am J Gastroenterol 2015:110:1490-6.

25 Lai SW, Lin CL, Liao KF. Association of meloxicam use with the risk of acute pancreatitis: a case-control study. Clin Drug Investig 2015;35:653-7.
26 Lai SW, Lin CL, Liao KF, et al. Parkinson's disease and hepatocellular carcinoma in older people: a population-based case-control study in Taiwan. Int Med J 2015;22:313-14.

27 Liao KF, Lin CL, Lai SW, et al. Sitagliptin use and risk of acute pancreatitis in type 2 diabetes mellitus: a population-based case-control study in Taiwan. Eur J Intern Med 2016:27:76-9.

28 Lai SW, Liao KF, Lin CL, et al. Pyogenic liver abscess correlates with increased risk of acute pancreatitis: a population-based cohort study. J Epidemio 2015;25:246-53

29 Lai SW, Lai HC, Lin CL, et al. Finasteride use and acute pancreatitis in Taiwan. J Clin Pharmacol 2015;55:657-60.

30 Lai SW, Lin CL, Liao KF. Increased relative risk of acute pancreatitis in zolpidem users. Psychopharmacology (Berl) 2015;232:2043-8.

31 Liao K-F, Lin C-L, Lai S-W, et al. Parkinson's disease and risk of pancreatic cancer: a population-based case-control study in Taiwan. Neurol Asia 2015:20:251-5.

32 Lai SW, Chen PC, Liao KF, et al. Risk of hepatocellular carcinoma in diabetic patients and risk reduction associated with anti-diabetic therapy: population-based cohort study. Am J Gastroenterol 2012;107:46-52.

33 Liao KF, Lin CL, Lai SW, et al. Zolpidem use sssociated with increased risk of pyogenic liver abscess: a case-control study in Taiwan. Medicine 2015;94: e1302.

34 Lai SW, Lin CL, Chen WC, et al. Correlation between use of zopiclone and risk of hip fracture in elderly adults: a case-control study in Taiwan. J Am Geriatr Soc 2015;63:2534-7.

35 Lai SW, Lin CL, Liao KF. Atorvastatin use associated with acute pancreatitis: a case-control study in Taiwan. Medicine (Baltimore) 2016:95:e2545.

36 Eland IA, Sundström A, Velo GP, et al. Antihypertensive medication and the risk of acute pancreatitis: the European case-control study on drug-induced acute pancreatitis (EDIP). Scand J Gastroenterol 2006;41:1484-90.

37 Sjöberg Bexelius T, García Rodríguez LA, Lindblad M. Use of angiotensin II receptor blockers and the risk of acute pancreatitis: a nested case-control study. Pancreatology 2009;9:786-92.

38 Tsang SW, Cheng CH, Leung PS. The role of the pancreatic renin-angiotensin system in acinar digestive enzyme secretion and in acute pancreatitis. Regul Pept 2004;119:213-19.

39 Leung PS, Ip SP. Pancreatic acinar cell: its role in acute pancreatitis. Int J Biochem Cell Biol 2006:38:1024-30.

40 Skipworth JR, Szabadkai G, Olde Damink SW, et al. Review article: pancreatic renin-angiotensin systems in health and disease. Aliment Pharmacol Ther 2011;34:840-52

41 Tsang SW, Ip SP, Leung PS. Prophylactic and therapeutic treatments with AT 1 and AT 2 receptor antagonists and their effects on changes in the severity of pancreatitis. Int J Biochem Cell Biol 2004;36:330-9.

42 Oruc N, Ozutemiz 0 , Nart D, et al. Inhibition of renin-angiotensin system in experimental acute pancreatitis in rats: a new therapeutic target? Exp Toxicol Pathol 2010:62:353-60.

43 Haddad AM, Scholer SG. Possible losartan-induced rash. Am J Health Syst Pharm 1997:54:1333-4. 